\title{
Indoleacetic Acid Levels in Wheat and Rice Seedlings under Oxygen Deficiency and Subsequent Reoxygenation
}

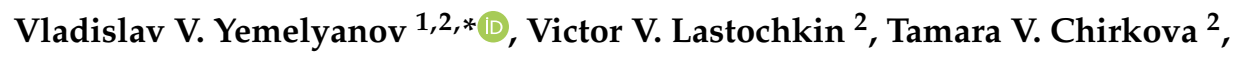 \\ Sylvia M. Lindberg ${ }^{3}\left(\mathbb{D}\right.$ and Maria F. Shishova ${ }^{2}(\mathbb{D}$ \\ 1 Department of Genetics and Biotechnology, Saint-Petersburg State University, Universitetskaya em., 7/9, \\ 199034 Saint-Petersburg, Russia \\ 2 Department of Plant Physiology and Biochemistry, Saint-Petersburg State University, Universitetskaya em., \\ 7/9, 199034 Saint-Petersburg, Russia; viclast@list.ru (V.V.L.); mim39@mail.ru (T.V.C.); \\ mshishova@mail.ru (M.F.S.) \\ 3 Department of Ecology, Environment and Plant Sciences, Stockholm University, SE-106 91, Stockholm, \\ Sweden; sylvia.lindberg@su.se \\ * Correspondence: bootika@mail.ru; Tel.: +79-219-891-421
}

Received: 31 December 2019; Accepted: 10 February 2020; Published: 11 February 2020

\begin{abstract}
The lack of oxygen and post-anoxic reactions cause significant alterations of plant growth and metabolism. Plant hormones are active participants in these alterations. This study focuses on auxin-a phytohormone with a wide spectrum of effects on plant growth and stress tolerance. The indoleacetic acid (IAA) content in plants was measured by ELISA. The obtained data revealed anoxia-induced accumulation of IAA in wheat and rice seedlings related to their tolerance of oxygen deprivation. The highest IAA accumulation was detected in rice roots. Subsequent reoxygenation was accompanied with a fast auxin reduction to the control level. A major difference was reported for shoots: wheat seedlings contained less than one-third of normoxic level of auxin during post-anoxia, while IAA level in rice seedlings rapidly recovered to normoxic level. It is likely that the mechanisms of auxin dynamics resulted from oxygen-induced shift in auxin degradation and transport. Exogenous IAA treatment enhanced plant survival under anoxia by decreased electrolyte leakage, production of hydrogen peroxide and lipid peroxidation. The positive effect of external IAA application coincided with improvement of tolerance to oxygen deprivation in the 35S:iaaM $\times 35 \mathrm{~S}: i a a H$ lines of transgene tobacco due to its IAA overproduction.
\end{abstract}

Keywords: auxin; oxygen deficiency; post-anoxia; rice; tobacco; wheat

\section{Introduction}

Plant growth is a complicated process under the control of multiple internal and external effectors. Plant response is always the sum of positive and negative alterations appearing at molecular, cell, tissue and organism levels. Nowadays modeling provides an efficient way to elucidate systemic plant response [1]. Each of the stressors has peculiar mechanisms of action involving activation of specific gene groups that trigger specific developmental, physiological and metabolic adaptations. Nevertheless, accumulated data suggest that there are possible integrative responses common for a group of factors, such as drought, salinity and chilling stress [2]. Here we aim to reveal some cross-adaptations to oxygen deficiency and further reoxygenation.

Higher plants strongly depend on ambient oxygen concentration. The plant facilities to survive oxygen deprivation have been studied for decades [3-7]. Partial (hypoxia) or complete lack of oxygen (anoxia) characterizes both natural and agricultural ecosystems and has a serious economic impact $[8,9]$. 
Global climate changes make increasingly relevant studies focused on mechanisms that ensure survival, growth and development of plants and minimize yield loss.

Resistance of plants to oxygen deficiency depends on a set of developmental, physiological and metabolic adaptations. There are two contrasting strategies behind such adaptations, low oxygen escape syndrome (LOES) and low oxygen quiescence syndrome (LOQS) [3]. The first one is based on a rapid shoot growth, hyponastic bending of leaves, formation of aerenchyma, initiation of adventitious roots, and alteration of leaf anatomy to improve the diffusion of gases, etc. [4-6]. This is a strategy to avoid oxygen deprivation by facilitating gas exchange between the submerged and aerated organs of plant. The quiescent strategy consists of fast growth termination and redirection of stored energy and carbohydrates in order to survive in an oxygen-deficient environment and enables growth recovery when normoxic conditions are restored [4-6]. ATP generated due to starch mobilization, glycolysis, and fermentation is used predominantly for the synthesis of proteins involved in energy metabolism, membrane transport, elimination of reactive oxygen species (ROS), and chaperone activity [5-7,9].

Both strategies are intensively regulated by phytohormones [10]. Ethylene plays a crucial role in plant response to oxygen deprivation [2,11,12]. Submergence induces synthesis and physical entrapment of ethylene inside plant tissues [5,13]. The ethylene accumulation activates a group of transcription factors - ethylene responsive factor VII (ERF-VII). The representatives of this group SNORKEL1 (SK1) and SNORKEL2 (SK2) in rice control escape strategy (LOES). They alter hormonal balance by accumulating gibberellins and decreasing abscisic acid leading to a fast internode elongation [14]. SKs are responsible for regulating carbohydrate breakdown for the provision of accelerated growth via activation of a number of protein kinases and transcription factors [12]. The quiescent strategy (LOQS) in rice is governed by SUBMERGENCE 1A (SUB1A, also belonging to ERF-VII). SUB1A suppresses ethylene and GA signaling [5], positively regulating the transcription of genes related to the fermentation and repressing of genes involved in carbohydrates metabolism [15].

In Arabidopsis thaliana, the ERF-VII factors also participate in the regulation of the anoxic response. Three factors RAP2 (RELATED TO AP2) - RAP2.2 (ERF75), RAP2.3 (ERF72/EBP) and RAP2.12 (ERF74) are constitutively synthesized during normoxia and elevated by ethylene [9]. Two other factors HRE (HYPOXIA RESPONSIVE ERF) - HRE1 (ERF73) and HRE2 (ERF71) are actively induced under oxygen deficiency [5]. These ERF-VII factors in the presence of oxygen very quickly pass proteolysis according to the N-terminus rule, while at low oxygen these TFs are stabilized and induce hypoxic gene expression $[5,12,16]$.

It is interesting that even at normoxia there are few examples of "hypoxic niches" existing inside the native plant body. One example is the uncontrolled cell proliferation of crown galls. Development of internal hypoxic conditions triggers the low-oxygen response pathway, mediated by ERF-VII group [17]. Another example is lateral root primordia. It has been shown that the ethylene-induced transcription factors of the ERF-VII group control root architecture. They decrease the expression of auxin-induced genes LBD16, LBD18 and PUCHI, encoding transcription factors essential for lateral root development [18].

Ethylene-auxin crosstalk is the major player that initiates stem hypertrophy and formation of adventitious roots during submergence in different plants $[5,10,13]$ via ethylene-dependent redistribution of auxin transport [19,20], accumulation [20-23] and increase in sensitivity to auxin (indoleacetic acid, IAA) in root-forming tissues [24]. Flooding induced hyponastic response of Rumex palustris petioles depending on auxin [25]. Epinasty in susceptible plants like tomato also depends on IAA-ethylene interactions [26]. Auxin affects growth during oxygen deficiency in a wide spectrum of wetland plants. It stimulates growth in leaves of the fern Regnellidium diphyllum [27], stems of Potamogeton pectinatus [28], petioles of Nymphoides peltata [29], Ranunculus sceleratus [30-32], and R. palustris [33]. On the other hand, auxin is not required for the ethylene-mediated submergenceinduced growth of coleoptiles [34] and internodes of the most studied LOES plant, the deep-water rice [35]. Under complete anoxia, IAA has no effect on the growth of excised coleoptiles [36]. 
Alterations of endogenous IAA level also vary in different plants during oxygen shortage. Submergence reduces total level of auxin in rice coleoptiles [37] and in petioles of R. palustris [25]. Wheat that is more susceptible to hypoxia shows less IAA increase under oxygen lack than the more tolerant oat [38,39]. Rice seedlings accumulated even higher amounts of IAA at total anoxia [40,41]. However, it is still unclear, what is the mechanism of auxin increase under oxygen deprivation, and how it affects plant organ/tissue tolerance.

An additional factor should be taken into consideration. The reestablishment of normal oxygen levels in the natural environment after hypoxia or anoxia provokes intensive oxidative damage to plants affecting growth and survival. Fast reentry of oxygen leads to an oxidation of reduced intermediate and end-products that accumulate during preceding anoxia, soil toxins, overproduction of ROS and other toxic oxidative products $[6,12,42]$.

ROS accumulation is well documented for wide spectra of abiotic interactions [43]. The origin of ROS in plant cell is different. The cell wall, plasma membrane, cytosol, mitochondria, chloroplasts, peroxisomes, glyoxysomes, and endoplasmic reticulum are known to participate in ROS production [44]. An important ROS source in leaf tissues is photosynthesis. Alterations in the photochemical efficiency of PSII in rice leaves were found specific for different stress factors such as high light, salinity, high osmolality, and heavy metal stress [45]. Alternatively, ROS generation is related to respiration and oxidative processes in plasma membrane/apoplast and peroxisomes [43,44]. These two mechanisms are supposed to be responsible for ROS elevation in roots. Surprisingly ROS accumulation was mentioned even under oxygen deprivation [46]. Some phospholipases D are also involved in ROS signaling under hypoxic stress [47].

In plant cells ROS degradation can be implemented by low molecular weight antioxidants (ascorbate, glutathione, tocopherol) and detoxifying enzymes (superoxide dismutases, catalases, and peroxidases). Many genes responsible for ROS utilization and antioxidant defense are triggered by hypoxia [48]. During reaeration, the immediate repletion of oxygen enhances the Arg/N-terminal pathway of ERF-VIIs degradation via plant Cys-oxidases, leading to the fast repression of anaerobic mRNAs' transcription. On the other hand, in A. thaliana, reoxygenation promotes accumulation of transcripts associated with ethylene production [5]. This suggests that ethylene signaling plays a role during oxygen depletion stress recovery. Auxin is an important plant hormone regulating growth and development. Therefore, it may be involved in plant survival and recovery in the post-anoxic period.

Taken together the provided data reveal a complicated link between hypoxia trigged ethylene and auxin crosstalk. Different effects of auxin on shoot elongation and root architecture under oxygen deficiency might result from different levels of plant-organ sensitivity to oxygen deprivation and to multiple elements of auxin signaling and the systems related to its metabolism. It is questionable as to whether auxin itself has a direct effect on plant growth and biochemical adaptation to oxygen deficiency. Even more puzzling is the role auxin plays under increased levels of ROS concentration in plant tissues during post-hypoxic/-anoxic reoxygenation. This study focuses on the possible alteration of auxin level in organs of plants differing in sensitivity to a lack of oxygen. It reveals the importance of exogenous IAA treatment or its overproduction in transgenic plants as well as the means by which it regulates plant survival under conditions of oxygen deprivation.

\section{Materials and Methods}

\subsection{Plant Material and Growing Conditions}

Seeds of spring wheat (Triticum aestivum L. cv. Leningradka) were purchased from Suida Breeding Station (Leningrad Region, Russia) and seeds of japonica rice (Oryza sativa L. cv. Liman) were obtained from the All-Russian Rice Research Institute (Krasnodar, Russia). The seeds were surface-sterilized with $5 \% \mathrm{NaClO}$ solution $(v / v)$ for $15 \mathrm{~min}$, washed several times in distilled water, and soaked for $1 \mathrm{~h}$ in hot water at $45-50{ }^{\circ} \mathrm{C}$ for wheat and at $50-55^{\circ} \mathrm{C}$ for rice. After germination for two days in the dark at $23^{\circ} \mathrm{C}$ for wheat and at $28^{\circ} \mathrm{C}$ for rice, the seedlings were planted in perforated plastic plates of beakers filled 
with continuously aerated Knop nutrient solution ( 0.2 strength) and grown at an irradiance of $100 \mathrm{~W} / \mathrm{m}^{2}$, at a photoperiod of $14 \mathrm{~h}$ (for wheat) and $12 \mathrm{~h}$ (for rice) at $22-25^{\circ} \mathrm{C}$ as described previously [41].

Seeds of wild type tobacco (Nicotiana tabacum L. cv. Wisconsin 38) and transgenic IAA-overproducing lines 16:15, 18:13 and $1 \times 2$ a were kindly supplied by Prof. Folke Sitbon (Uppsala BioCenter, Swedish University of Agricultural Sciences, Uppsala, Sweden). In this study we used transgenic lines created by crossing primary transformants expressing the Agrobacterium tumefaciens IAA biosynthesis genes iaaM and iaaH under control of $35 \mathrm{~S}$ promoters. 35S:iaaM $\times 35$ S:iaaH plants accumulate $2-3$ times higher auxin in leaves and stems than the wild type $[49,50]$. Tobacco seeds were first surface-sterilized with $70 \%$ ethanol $(v / v)$ for $5 \mathrm{~min}$, washed several times with sterile water, subsequently sterilized with $10 \%$ $\mathrm{NaClO}$ solution $(v / v)$ for $15 \mathrm{~min}$, washed again several times with sterile water and germinated in Petri dishes on a solid MS basal medium [51] supplemented with sucrose (20 g/L) and Gelrite ${ }^{\mathrm{TM}}$ (Duchefa Biochemie, Haarlem, The Netherlands; $30 \mathrm{~g} / \mathrm{L}$ ). After a week seedlings were transferred to the same medium in 1 liter sterile glass jars (3 plants per jar) and grown for another 3-4 weeks at a temperature of $22-25^{\circ} \mathrm{C}$ with a $16 \mathrm{~h}$ photoperiod.

\subsection{Imposition of Anoxic and Post-Anoxic Conditions, IAA Treatment}

For measurement of endogenous auxin content a part of the cereal seedlings were analyzed as the initial material (time point 0 ), and the other seedlings were separated into control and experimental groups. Each set of twenty seedlings were placed in glasses containing $20 \mathrm{~mL}$ of Knop nutrient solution (0.2 strength). Glasses were placed into the chamber through which gaseous nitrogen containing less than $0.01 \%$ of oxygen was purged for $45 \mathrm{~min}$ in order to create anaerobic conditions. Then, the chambers were hermetically closed and put in the dark in order to prevent oxygen formation in the light. Anaerobic conditions were checked using Anaerotest ${ }^{\circledR}$ indicator (Merck, Darmstadt, Germany). Duration of anoxic exposure was $12 \mathrm{~h}$. Control seedlings were kept in dark at normal oxygen level (21\%). For modeling post-anoxia anaerobic chambers were opened and plants were transferred into aerobic atmosphere for 1, 6, 24, 72 and $144 \mathrm{~h}$ after exposing to anoxia. After $24 \mathrm{~h}$ of reoxygenation plants were exposed to light.

For investigation of auxin effects on plant viability and oxidative processes seedlings were treated with $10 \mu \mathrm{M}$ IAA dissolved in Knop nutrient solution ( 0.2 strength) for 1 day in the dark before the imposition of anoxia, i.e. the hormone was supplied via roots. In preliminary experiments, concentrations of IAA were tested in the range from $10^{-8}$ to $10^{-4} \mathrm{M}$, and $10^{-5} \mathrm{M}(10 \mu \mathrm{M})$ was the most effective (data not shown).

When testing anoxia effect on IAA-overproducing tobacco sterile glass jars with plants were opened, placed into the anaerobic chamber and flushed with gaseous nitrogen as described above. The duration of anoxic treatment was 4 hours. Control plants were kept at the open air.

\subsection{Quantification of Endogenous IAA}

IAA was extracted, purified and quantified by ELISA as previously described [41] with some modifications. Shoots and roots of ten seedlings (0.3-1 g of fresh weight (FW)) were ground in liquid nitrogen. Thoroughly homogenized plant material was transferred into centrifuge tubes with 10 volumes of cold $80 \%$ methanol $(v / v)$ containing $400 \mathrm{mg} / \mathrm{mL}$ of sodium diethyldithiocarbamate, and Polyclar AT (Serva, Heidelberg, Germany; $10 \%$ based on the plant the material weight). The extraction was performed overnight at $4{ }^{\circ} \mathrm{C}$. After centrifugation at $12,000 \times \mathrm{g}$ for $20 \mathrm{~min}$ the supernatant was collected and the pellet was washed three times for $30 \mathrm{~min}$ with $1 / 2$ of the initial methanol volume. The combined extract was passed through the Sep-Pak C18 column (Waters, Milford, MA, USA) two times and IAA was eluted from the column with $10 \mathrm{~mL}$ of $80 \%$ methanol $(v / v)$. Then methanol was evaporated to water phase in the refrigerated CentriVap centrifugal concentrator (Labconco, Kansas City, MO, USA) at $10{ }^{\circ} \mathrm{C}$, and the water phase was diluted to $3 \mathrm{~mL}$ with deionized water, and $\mathrm{pH}$ was adjusted to 2.8-3.0 with $1 \mathrm{~N} \mathrm{HCl}$. Further IAA was extracted three times with equal volumes of ethyl acetate. The organic phase was collected and combined extract was evaporated to dryness in CentriVap 
(Labconco). Dried samples were dissolved in 100\% methanol and IAA was subsequently purified by TLC. Separation was performed for $1 \mathrm{~h}$ in isopropanol:28\% ammonia:water (10:1:1, v/v/v) system in Silufol-254 UV plates (Kavalier, Votice, Czech Republic). IAA bands (Rf 0.35-0.40) were scraped off from chromatography plates into micro tubes and extracted with $70 \%$ ethanol $(v / v)$. IAA was methylated with diazomethane produced from nitrosomethylurea. Alcoholic solutions of Met-IAA were used for the solid-phase immunoenzyme analysis. Solution of Met-IAA produced by diazomethane methylation of a known amount of IAA was used as a standard. Immunoassay of auxins was performed with reagents obtained and characterized as described by Veselov et al. [52]. The reagents were kindly provided by Prof. Stanislav Yu. Veselov (Bashkir State University, Ufa, Russia) and Prof. Farida M. Shakirova (Institute of Biochemistry and Genetics, RAS, Ufa, Russia). ELISA was performed with standard flat bottom polystyrene 96-well plates (Sarstedt, Nümbrecht, Germany). Measurements were done by ELISA analyzer FFM-1 (Cortek, Moscow, Russia) at $492 \mathrm{~nm}$. The IAA content in plant tissues was determined from the standard curve and calculated in pmol per $\mathrm{g}$ FW.

\subsection{Electrolyte Leakage Test}

Electrolyte leakage was measured from shoots and roots of control, anoxic and IAA-pretreated anoxic plants. Collected shoots and roots from 10 seedlings were placed separately in the test tubes and incubated in $10 \mathrm{~mL}$ of deionized water for $5 \mathrm{~h}$ in dark at room temperature [53], then electrical conductance (EC) was measured using conductivity meter HI2300 (Hanna Instruments, Woonsocket, RI, USA). Thereafter, plant samples were boiled in the same water for $30 \mathrm{~min}$ to induce total leakage and cooled to room temperature before measurement. Relative electrolyte leakage was calculated according to the formula:

$$
\operatorname{EL}(\%)=\left(\mathrm{EC}_{\mathrm{L}} / \mathrm{EC}_{\mathrm{T}}\right) \times 100 \%
$$

where $\mathrm{EC}_{\mathrm{L}}$ is the electrical conductance of leaked electrolytes at room temperature, and $\mathrm{EC}_{\mathrm{T}}$ represents the total electrical conductance after boiling.

\subsection{Evans Blue Staining}

The level of cell damage in tobacco after anoxic treatment was measured by Evans blue staining assay $[54,55]$. Ten leaf discs (10 mm diameter) were weighed and incubated with $3 \mathrm{~mL} 0.05 \%$ Evans blue (w/v) in $20 \mathrm{mM}$ MES (pH 5.8) on the shaker at $100 \mathrm{rpm}$ for $30 \mathrm{~min}$ at room temperature. After the incubation the discs were washed three times with $20 \mathrm{mM}$ MES to remove excess of Evans blue dye, placed into $2 \mathrm{~mL}$ micro tubes, ground with $1 \mathrm{~mL}$ of $1 \%$ SDS $(w / v)$ in $50 \%$ methanol $(v / v)$, and incubated for a further $30 \mathrm{~min}$ at $50{ }^{\circ} \mathrm{C}$ to release the absorbed dye from the plant tissues. Following centrifugation at $9000 \times g$ for $5 \mathrm{~min}$, optical density of supernatant was measured at $600 \mathrm{~nm}$ (U-2000 spectrophotometer, Hitachi, Tokyo, Japan). The cell damage was calculated in $\mu$ mol of Evans blue absorbed by plant tissues per $\mathrm{g}$ of FW.

\subsection{Thiobarbituric Acid Reactive Substances Assay}

Level of lipid peroxidation was evaluated using thiobarbituric acid as described earlier [56]. Roots of ten seedlings (about $1 \mathrm{~g}$ ) were thoroughly homogenized with quartz sand, mixed with $5 \mathrm{~mL}$ of $0.1 \%$ TCA $(w / v)$. After filtration $0.5 \%$ thiobarbituric acid $(w / v)$ in $20 \%$ TCA $(w / v)$ was added to an aliquot of the filtrate, then the mixture was incubated in a boiling water bath for $30 \mathrm{~min}$. After cooling and centrifugation at $8000 \times g$ for $20 \mathrm{~min}$, absorbance of the supernatant was measured at $532 \mathrm{~nm}$ (UNICO 2800H UV/VIS spectrophotometer, Dayton, NJ, USA). The amount of thiobarbituric acid reactive substances (TBARS) was calculated per $\mathrm{g}$ FW using malondialdehyde extinction coefficient $(0.156 \times 1 /(\mu M \times c m))[57]$.

\subsection{Xylenol Orange Assay}

Hydrogen peroxide production was measured using the xylenol orange assay [58] after the incubation of plant material (roots of 10 seedlings) in $15 \mathrm{~mL}$ of $50 \mathrm{mM}$ phosphate buffer ( $\mathrm{pH}$ 6.0) for 
$30 \mathrm{~min}$. The working reagent contained $0.1 \mathrm{~mL}$ of $25 \mathrm{mM} \mathrm{FeSO}_{4}$ and $25 \mathrm{mM}\left(\mathrm{NH}_{4}\right)_{2} \mathrm{SO}_{4}$ in $2.5 \mathrm{M} \mathrm{H}_{2} \mathrm{SO}_{4}$, and $10 \mathrm{~mL}$ of $125 \mu \mathrm{M}$ xylenol orange and $100 \mathrm{mM}$ sorbitol [59]. The assay mixture consisted of $0.1 \mathrm{~mL}$ of the incubation solution and $3 \mathrm{~mL}$ of the working reagent. After $30 \mathrm{~min}$ in the dark absorbance was measured at $560 \mathrm{~nm}$ (UNICO $2800 \mathrm{H}$ UV/VIS spectrophotometer). The amount of $\mathrm{H}_{2} \mathrm{O}_{2}$ produced was determined from a standard curve and calculated in nmol per $\mathrm{g}$ FW per min. The specificity of the assay was confirmed by the inhibition of hydrogen peroxide production by 500 units of catalase.

\subsection{Statistics}

Data on the figures are presented as mean \pm SE for $\geq 5$ experiments. Analysis of variance was done with GraphPad Prism 5 for Windows).

\section{Results}

\subsection{Effects of Anoxia and Reoxygenation on IAA Content in Wheat and Rice}

Before the imposition of anoxia (time point 0 ), shoots of wheat seedlings contained about twice as much IAA as the roots and rice shoots (Figure 1).

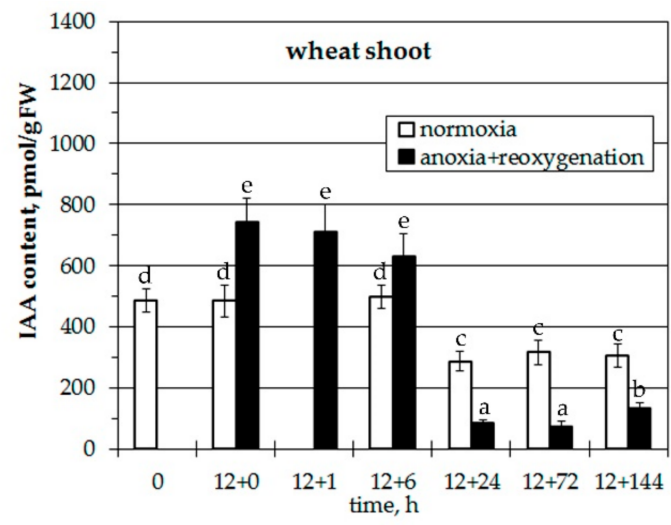

(a)

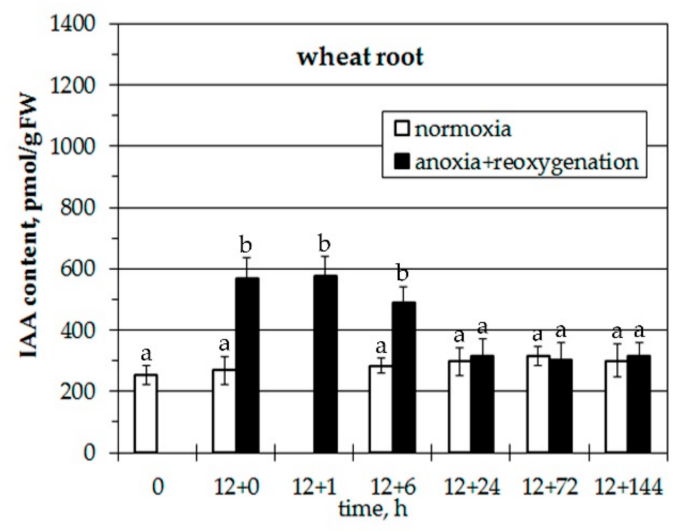

(c)

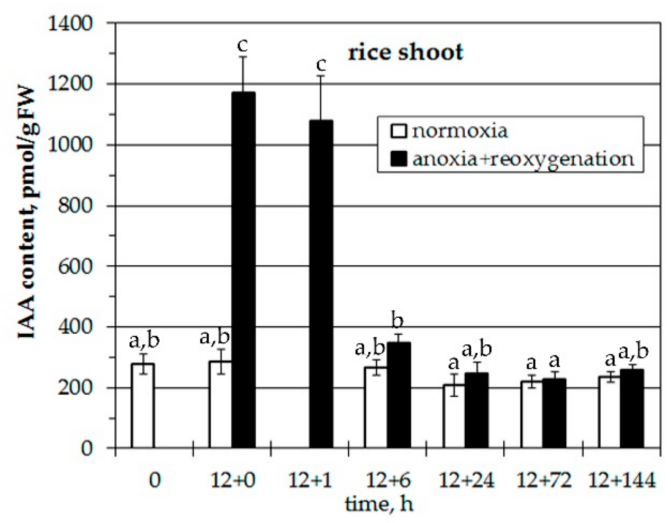

(b)

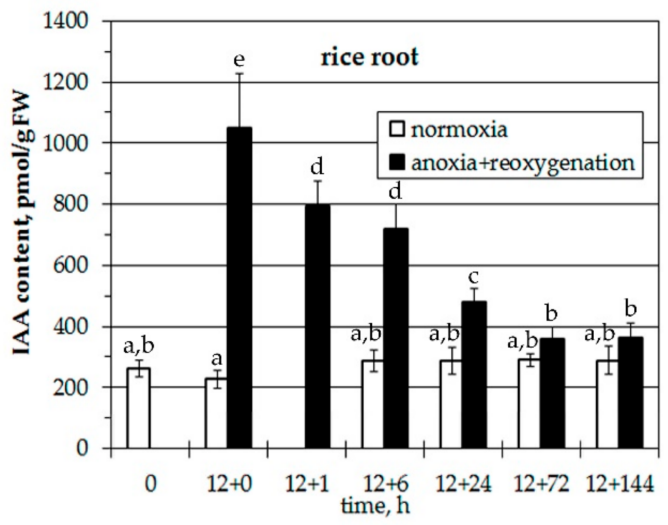

(d)

Figure 1. Effect of anoxia (12 h) and reoxygenation $(+1$ to $+144 \mathrm{~h})$ on IAA content in shoots $(\mathbf{a}, \mathbf{b})$ and roots $(\mathbf{c}, \mathbf{d})$ of wheat $(\mathbf{a}, \mathbf{c})$ and rice $(\mathbf{b}, \mathbf{d})$ seedlings. Values with the different letters are significantly different at $p<0.05$, according to post-hoc LSD test.

Rice roots and shoots accumulated about the same amount of free IAA. $12 \mathrm{~h}$ of anoxic treatment $(12+0$ point) led to a rise of IAA level by $50 \%$ in wheat shoots (Figure $1 \mathrm{a})$ which was maintained until $6 \mathrm{~h}$ of reoxygenation followed by a significant decrease to about $20 \%-30 \%$ of normoxic and $10 \%$ of anoxic level. An anoxia-induced increase of IAA levels in wheat roots was twofold (Figure 1c). After 
$24 \mathrm{~h}$ of reaeration it returned to initial/control normoxic level and was maintained until the end of the experiment. Shoots and roots of rice seedlings reacted to anoxia and subsequent aeration in a similar manner (Figure 1b,d). Oxygen deprivation brought about significant accumulation of free IAA (4-fold in shoots and 5-fold in roots) followed by decrease of hormone content to normoxic levels at $6 \mathrm{~h}$ of reoxygenation in shoots and $72 \mathrm{~h}$ in roots.

Thus, $12 \mathrm{~h}$ of anoxia led to an increase of auxin content in plant tissues, especially in rice roots and shoots. Rice roots accumulated higher amounts of hormone during anoxia and restored its initial before-stress level in shoots at reaeration while in shoots of wheat seedlings it was reduced compared with normoxia. The level of IAA returned mainly to normoxic level both in roots of wheat and rice seedlings during reoxygenation.

\subsection{Effects of Pretreatment with IAA and IAA Overproduction on Anoxia-Induced Plant Damage}

In order to determine whether IAA accumulation in plant tissues during short-term anoxia does or does not have a protective action on plant survival, wheat and rice seedlings were treated with $10 \mu \mathrm{M}$ IAA administrated via root system before anoxic exposure. After $12 \mathrm{~h}$ of anoxia the relative electrolyte leakage (EL) was measured form shoots and roots of normoxic, anoxic and IAA-pretreated anoxic seedlings (Figure 2). Electrolyte leakage assay evaluates the integrity of cell membranes and a higher leakage value corresponds to higher degree of cell damage.

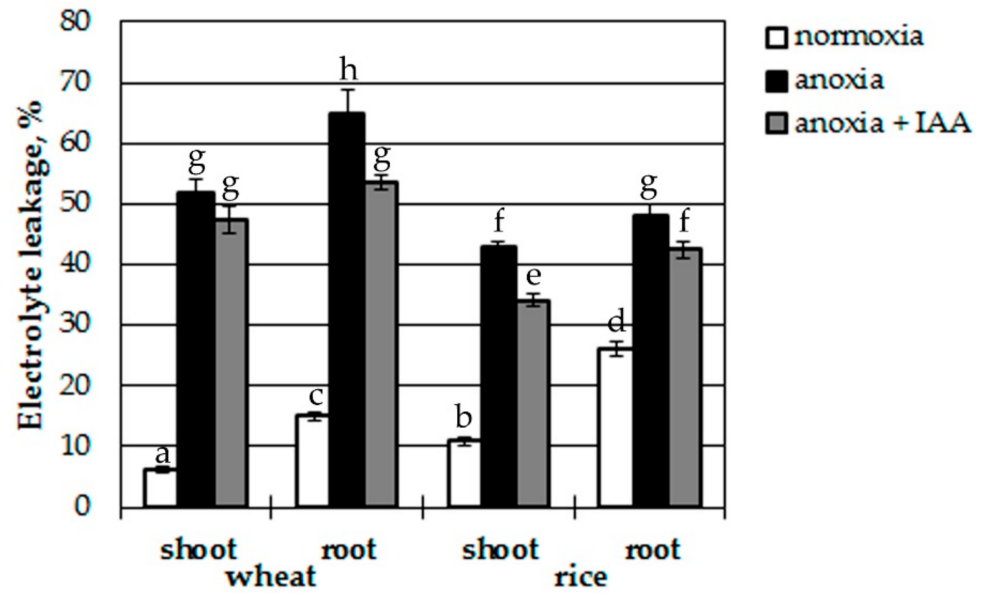

Figure 2. Effect of treatment with IAA $(10 \mu \mathrm{M})$ on anoxia-induced electrolyte leakage from wheat and rice seedlings. Values with the different letters are significantly different at $\mathrm{P}<0.05$, according to post-hoc LSD test.

Surprisingly, the level of EL form tissues of wheat seedlings was lower than from rice seedlings at normoxic conditions. EL from roots was 2-2.5 times higher than from shoots of both plants. The effect of anoxia resulted in drastic stimulation of EL from wheat seedlings (8-fold in shoots and 4-fold in roots). Auxin pretreatment had no significant effect on anoxia-induced EL from wheat shoots, but reduced damage in wheat roots by $18 \%$. In rice seedlings anoxia led to only 4 -fold increase of EL in shoots and 2-fold in roots reflecting a higher tolerance of rice to oxygen deprivation. IAA treatment prior to anoxia lowered EL by $10 \%-15 \%$ in shoots and roots of rice seedlings. Thus, IAA treatment favors membrane integrity during anoxia.

Data on treatment with exogenously supplied hormones are not always relevant since part of the hormone can be degraded or not absorbed and the administration through the root system affects its translocation within plant. Therefore, we used tobacco plants with endogenously elevated IAA level. 35S:iaaM × 35S:iaaH plants exhibited leaf curling, epinasty and intensified formation of adventitious roots at stem and petioles due to accumulation of 2-3 times higher IAA in leaves and stems than the wild type [49,50]. Evans blue staining assay was carried out to evaluate the possible effect of high auxin content on anoxia-induced cell damage (Figure 3). Evans blue dye enters only in dead cells with 
a freely permeable plasma membrane, therefore, a higher staining level corresponds to higher damage. Staining with Evans blue was similar in all tested tobacco plants, wild type and IAA-overproducing transgenes at normoxia. Imposition of $4 \mathrm{~h}$ anoxia brought about significant increase of dye absorption in all plants too, but it was about 5-fold in wild type plants, whereas in 35S:iaaM $\times 35$ S:iaaH lines it did not exceed 3 folds, i.e. all IAA-overproducing plants were less damaged by anoxia.

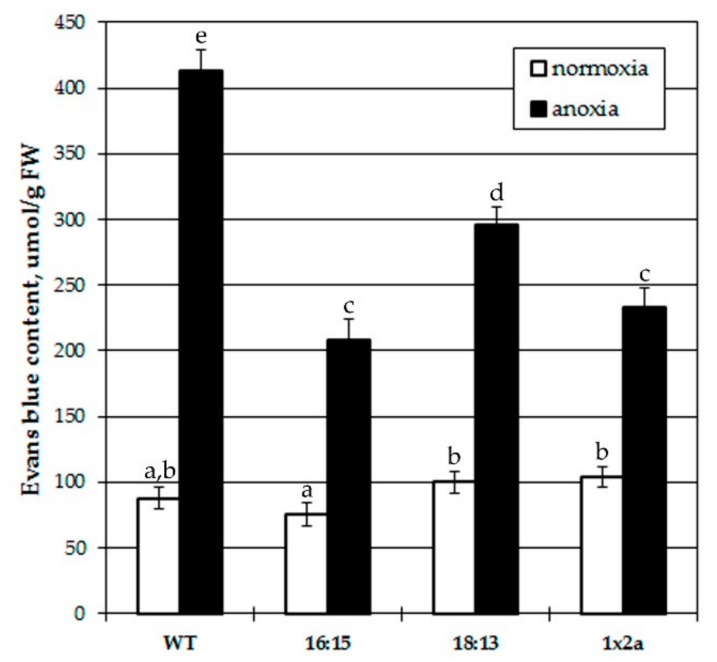

Figure 3. Effect of anoxia on cell damage in wild type (WT) tobacco and 35S:iaaM $\times 35$ S:iaaH lines $(16: 15,18: 13$ and $1 \times 2)$ overproducing IAA. Values with the different letters are significantly different at $p<0.05$, according to post-hoc LSD test.

\subsection{Effects of Plant Pretreatment with IAA on Oxidative Processes after Anoxia}

The viability tests used in this study, such as electrolyte leakage and Evans blue staining, reflect cell membrane integrity, which may be disturbed by lipid peroxidation due to production of reactive oxygen species, e.g., $\mathrm{H}_{2} \mathrm{O}_{2}$. Therefore, the effects of plant pretreatment with IAA on lipid peroxidation and $\mathrm{H}_{2} \mathrm{O}_{2}$ production at oxygen deprivation were assessed as well (Figure 4). We tested roots of seedlings for several reasons: (1) during treatment the hormone enters roots first, (2) since IAA treatment showed significant effects on the roots of both tested plants (Figure 2), and (3) since $\mathrm{H}_{2} \mathrm{O}_{2}$ production is easy to measure in roots.

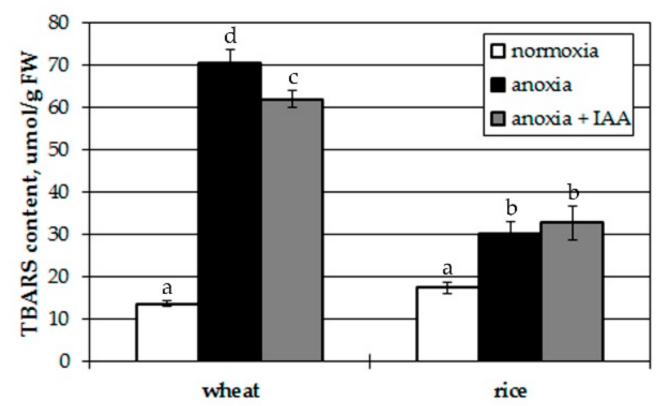

(a)

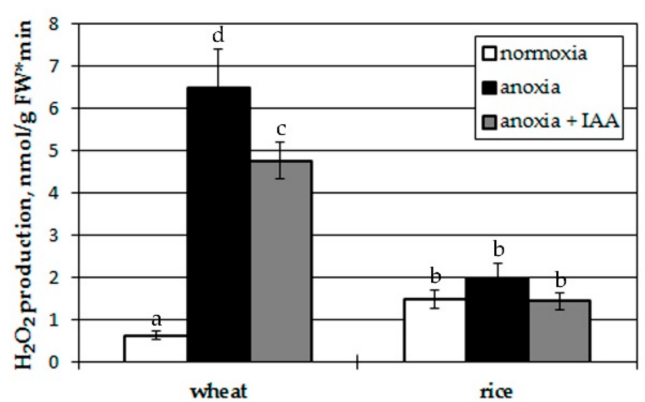

(b)

Figure 4. Effect of treatment with IAA $(10 \mu \mathrm{M})$ on lipid peroxidation (a) and hydrogen peroxide production $(\mathbf{b})$ in the roots of wheat and rice seedlings after $12 \mathrm{~h}$ anoxia. Values with the different letters are significantly different at $p<0.05$, according to post-hoc LSD test.

Anoxia led to a 5-fold increase of TBARS content in roots of wheat seedlings, corresponding to the lipid peroxidation level, and application of $10 \mu \mathrm{M}$ IAA suppressed it by $13 \%$ (Figure $4 \mathrm{a}$ ). In roots of rice seedlings a lack of oxygen provoked only 2-fold stimulation of lipid peroxidation which was unaffected by IAA treatment. 
Anoxic treatment in wheat led to a 10-fold increase of hydrogen peroxide production (Figure $4 \mathrm{~b}$ ), and IAA reduced it by one third. There were no significant changes found in $\mathrm{H}_{2} \mathrm{O}_{2}$ production in rice roots during anoxia and post-anoxic reoxygenation. Thus, IAA pretreatment prior to anoxia provided inhibition of destructive oxidative processes in wheat seedlings, but had no effects on rice.

\section{Discussion}

The obtained data showed a significant accumulation of free IAA in plant tissues during $12 \mathrm{~h}$ of anoxia (Figure 1). There was 1.5-2-fold rise of IAA level in wheat seedlings and 4-5-fold increase in rice. Earlier we reported a similar IAA accumulation in cereal seedlings at short-term (6-12 h) anoxia [41]. After the first transient peak of accumulation, IAA level decreased to initial normoxic level in wheat seedlings and continued to increase in rice finishing to 5-7-fold level after 3 days of anoxia [41]. A similar auxin content dynamics in rice after 1-3 days of anoxia was reported by Mapelli et al. [40]. A medium hypoxia tolerant oat demonstrated an intermediate IAA level between sensitive wheat and tolerant rice in oxygen-deprived environment $[38,39]$. The present data testify that plants resistant to anoxia are characterized by a higher level of anoxia-induced IAA. The mechanisms of IAA accumulation are still enigmatic. Different pathways of biosynthesis, polar transport, conjugation and degradation are supposed to regulate IAA concentration. It is unlikely that oxygen deprivation intensifies auxin synthesis, since synthesis directly depends on molecular oxygen. It might block the reversible $\beta$-oxidation of indolebutyric acid responsible for the generation of active IAA [60]. Another way of IAA over accumulation during oxygen deficiency may be suppression of oxidative breakdown. We reported inactivation of IAA oxidase being more severe for tissues of medium tolerant oat seedlings [38]. Another enzyme of auxin degradation is DIOXYGENASE FOR AUXIN OXIDATION (DAO) converting IAA to oxIAA. Alteration of the activity of DAO owing to mutations leads to a phenotype with elevated auxin levels. Both reactions are provided by oxidation and supposed to be down-regulated during anoxia. However, the intensity of this down-regulation might depend on tissue origin and sensitivity of plant species to the lack of oxygen [61]. Additional mutations in DAO resulted in upregulation of gene encoding GH3s family responsible for IAA conjugation, which makes the system even more complex. The auxin level in plant tissues may also be changed via redistribution of PIN transporters. Stimulation of expression of genes encoding PIN1-2, PIN2 and IAA-GH3 was reported during induction of adventitious roots in Solanum dulcamara under partial and complete submergence [62]. It is worth noting that the level of auxin did not change.

During further reoxygenation the IAA level decreases rapidly in shoots and gradually in roots of both resistant and sensitive plants (Figure 1). Perhaps this is due to the higher availability of oxygen in shoots, where auxin is rapidly metabolized through the activation of different peroxidases by ROS under conditions of post-anoxia [63]. Note that in sensitive wheat seedlings the decrease in IAA content was more prolonged in shoots during reoxygenation, while in rice it rapidly recovered to normoxic level. Probably this effect might be an indicator of plant facility to tolerate oxygen shortage.

The EL test showed higher tolerance of rice seedlings than wheat ones, since they were less damaged (Figure 2). Treatment of seedlings with exogenous IAA reduced cell damage measured by EL tests in roots of both plants tested and in shoots of rice seedlings (Figure 2). In wheat shoots, the auxin effect was insignificant, and it was distinguished by a lower level of IAA during reoxygenation, again pointing out a lesser degree of oxygen-deficiency tolerance. The IAA treatment also provided inhibition of destructive oxidative processes (lipid peroxidation and hydrogen peroxide production; Figure 4) in wheat seedlings while it had little effect on rice. In rice the anoxia-induced oxidative processes were undistinguishable from normoxic control both in auxin-treated and auxin-untreated seedlings. This could be a reflection of higher tolerance on the part of rice to oxygen deprivation, or it could be the result of a higher endogenous IAA content.

Over the last decade there has been a wide spectrum of investigations concerning IAA and ROS interaction. Usually, IAA treatment stimulates ROS production and ROS production, in turn, intensifies oxidative IAA breakdown [64-68]. Our data on IAA treatments contradict these findings; but there are 
also reports showing the opposite effect of IAA treatment. IAA application to maize roots resulted in inhibition of growth that was accompanied by a reduction of ROS production [69]. Hormone-induced elevation of tolerance to different abiotic stresses was demonstrated for cytokinines [70]. Recently rice seedlings were shown to increase adaptation after exogenous salicylic acid and $\mathrm{H}_{2} \mathrm{O}_{2}$ application at osmotic stress [71].

Results from plant treatment with exogenous IAA inspired us to test tobacco plants with endogenously elevated IAA level. 35S:iaaM $\times 35$ S:iaaH plants contained 2-3 times higher IAA in leaves and stems than the wild type $[49,50]$. All tested IAA-overproducing tobacco plants were less damaged by anoxia than the wild type plant (Figure 3), endorsing a positive IAA role in providing plant survival during oxygen shortage and subsequent reoxygenation.

Another effect of auxin is to promote the growth of coleoptiles, both by itself and by triggering the synthesis of ethylene [72]. In some species, auxin, more than gibberellins, is required for ethylenemediated growth response to submergence conditions [32]. Nevertheless, a number of studies have shown that exogenous IAA does not affect the elongation of isolated coleoptiles and intact rice seedlings [36,73]. IAA participates in metabolic regulation during oxygen deficiency. Treatment with IAA increases ADH activity in lettuce [74], protein synthesis and accumulation of solutes in rice coleoptiles [75]. Auxin affects hyponastic response [33] and stimulates adventitious rooting [23].

Such a variety of feedback is commonly associated with alteration in plant cell sensitivity to the hormone. The auxin signaling pathway starts with receptors such as TRANSPORT INHIBITOR RESPONSE1 (TIR1) [76]. Further ubiquitination of Aux/IAA proteins results in release of ARF transcription factors. The involvement of auxin transduction elements in regulation of adaptive reaction on oxygen deprivation is in agreement with recently discovered data.

Hypoxia was found to inhibit lateral root formation due to both the IAA12-ARF5 auxin module and the IAA14-ARF7-ARF19 module [18]. It is known that the SAUR39 gene encoding small auxin-up RNA was shown to be sensitive to anoxia. It acts as a negative regulator of auxin biosynthesis and transport in rice coleoptiles. Overexpression of the SAUR39 gene leads to a reduction of free IAA levels and lower auxin transport in rice, which results in shoot shortage [77]. The signaling networks are realized not only at the transcriptional, but also at the microRNA level. miR160, miR164, miR167, miR171, miR390, and miR393 were found to be conserved within tested plant species and involved in auxin homeostasis and signal transduction [78]. Recently, miR164, miR167, and miR390 were found to decrease expression, whereas miR160 leads to its elevation in wild tomato roots treated with hypoxia [79].

Thus, the increase in the endogenous level of IAA can be considered specific to plant species and organ/tissues tolerant to oxygen deprivation. Other responses might be connected to alterations in sensitivity to the hormone and indicate that the auxin effect is a step in a complicated adaptation to flooding. This causes a minor damage effect under lack of oxygen and raises the plant tolerance. However, the mechanism of this hormone effect is still under investigation.

To date, there is no data on the role of IAA in post-anoxic conditions. Our experiments revealed a rapid decrease of shoot IAA level after plants were placed back to normoxia. The caused decrement in growth is apparently also a part of the adaptive mechanism, which allows the plant to exit the emergency growth mode when it reaches atmospheric air, and the plant switches to overcome the effects of oxidative stress, restores normal metabolic processes and continues to live under normal conditions without significant losses. The gradual restoration of the IAA level in the roots allows the plant to restore the level of root growth, not immediately upon returning to normal aeration conditions, but after a period of reparation after stress exposure.

Similar tendencies are observed in wheat plants, but they are less pronounced and, apparently, do not provide sufficient tolerance, since even after 6 days under normal conditions, wheat does not restore the initial level of the hormone content in shoots. Thus, a tolerant plant under conditions of both anoxia and early post-anoxic aeration differs from sensitive plant with an increased level of auxin. 


\section{Conclusions}

In the tolerant rice plant, IAA accumulated during anoxia. This phenomenon was repeatedly shown in earlier studies and confirmed by this study. During the post-anoxic period there was a quick return to the initial level of hormone content. This may indicate the importance of hormonal system in overcoming both anoxia and post-anoxia. In the sensitive wheat plant, the hormone accumulation at anoxia was not so pronounced, and reoxygention led to a decrease of hormone level compared with the control. This probably indicates an ineffective function of the hormonal system or hormone utilization in sensitive plants. A treatment with exogenous auxin was found to be most effective for wheat in increasing its resistance to anoxia and oxidative post-anoxic stress. Exogenous IAA treatment enhanced plant survival under anoxia by decreased electrolyte leakage, production of hydrogen peroxide and lipid peroxidation. The positive effect of external IAA application was confirmed with improvement of tolerance to oxygen deprivation in the 35S:iaaM $\times$ 35S:iaaH IAA-overproducing tobacco lines.

Auxin is an important regulator of a wide spectrum of processes. The obtained data emphasize the specific role of auxin in plant tolerance to anoxia and further reoxygenation. The mechanisms behind its function are still puzzling, but the involvement of regulation at several levels (transcription, level of RNA, alteration in activity of many enzymes and finally growth and metabolism, among others) allows us to suggest, that this role is a special one.

Author Contributions: All authors have read and agreed to the published version of the manuscript. Conceptualization, V.V.Y. and T.V.C.; methodology, V.V.Y. and S.M.L.; validation, V.V.Y., V.V.L. and M.F.S.; formal analysis, V.V.Y.; investigation, V.V.Y. and V.V.L.; data curation, T.V.C.; writing-original draft preparation, V.V.Y. and M.F.S.; writing—review and editing, V.V.Y., T.V.C., S.M.L. and M.F.S.; visualization, V.V.Y.; supervision, T.V.C.; project administration, V.V.Y.; funding acquisition, V.V.Y., S.M.L. and M.F.S.

Funding: This research was funded by Russian Foundation for Basic Research, grant numbers 18-04-00157a and 19-04-00655a, and by the Swedish Institute, grant number 01716/2005.

Acknowledgments: Authors would like to thank Prof. Folke Sitbon (Uppsala BioCenter, Swedish University of Agricultural Sciences, Uppsala, Sweden) for generous supply with seeds of wild type and auxin-overproducing tobacco. Generous gift of diagnostic reagents for detecting IAA by Prof. Stanislav Yu. Veselov (Bashkir State University, Ufa, Russia) and Prof. Farida M. Shakirova (Institute of Biochemistry and Genetics, RAS, Ufa, Russia) are greatly acknowledged. Research was performed using the equipment of the Center for Molecular and Cell Technologies of Research park of St. Petersburg State University.

Conflicts of Interest: The authors declare no conflict of interest. The funders had no role in the design of the study; in the collection, analyses, or interpretation of data; in the writing of the manuscript, or in the decision to publish the results.

\section{References}

1. Tardieu, F.; Tuberosa, R. Dissection and modelling of abiotic stress tolerance in plants. Curr. Opin. Plant Biol. 2010, 13, 206-212. [CrossRef] [PubMed]

2. Suzuki, N.; Rivero, R.M.; Shulaev, V.; Blumwald, E.; Mittler, R. Abiotic and biotic stress combinations. New Phytol. 2014, 203, 32-43. [CrossRef] [PubMed]

3. Voesenek, L.A.C.J.; Bailey-Serres, J. Flooding tolerance: $\mathrm{O}_{2}$ sensing and survival strategies. Curr. Opin. Plant Biol. 2013, 16, 647-653. [CrossRef] [PubMed]

4. Bailey-Serres, J.; Voesenek, L.A.C.J. Flooding stress: Acclimations and genetic diversity. Annu. Rev. Plant Biol. 2008, 59, 313-339. [CrossRef]

5. Voesenek, L.A.C.J.; Bailey-Serres, J. Flood adaptive traits and processes: An overview. New Phytol. 2015, 206, 57-73. [CrossRef]

6. Chirkova, T.; Yemelyanov, V. The study of plant adaptation to oxygen deficiency in Saint Petersburg University. Bio. Comm. 2018, 63, 17-31. [CrossRef]

7. Bailey-Serres, J.; Voesenek, L.A.C.J. Life in the balance: A signaling network controlling survival of flooding. Curr. Opin. Plant Biol. 2010, 13, 489. [CrossRef]

8. Dennis, E.S.; Dolferus, R.; Ellis, M.; Rahman, M.; Wu, Y.; Hoeren, F.U.; Grover, A.; Ismond, K.P.; Good, A.G.; Peacock, W.J. Molecular strategies for improving waterlogging tolerance in plants. J. Exp. Bot. 2000, 51, 89-97. [CrossRef] 
9. Bailey-Serres, J.; Lee, S.C.; Brinton, E. Waterproofing crops: Effective flooding survival strategies. Plant Physiol. 2012, 160, 1698-1709. [CrossRef]

10. Yemelyanov, V.V.; Shishova, M.F. The role of phytohormones in the control of plant adaptation to oxygen depletion. In Phytohormones and Abiotic Stress Tolerance in Plants; Khan, N.A., Nazar, R., Iqbal, A., Anjum, N.A., Eds.; Springer: Berlin/Heidelberg, Germany, 2012; pp. 229-248. [CrossRef]

11. Voesenek, L.A.C.J.; Sasidharan, R. Ethylene-And oxygen signalling-Drive plant survival during flooding. Plant Biol. 2013, 15, 426-435. [CrossRef]

12. Tamang, B.G.; Fukao, T. Plant adaptation to multiple stresses during submergence and following desubmergence. Int. J. Mol. Sci. 2015, 16, 30164-30180. [CrossRef] [PubMed]

13. Hu, Z.; Qi, X.; Zhang, M.; Chen, X.; Nakazono, M. Roles of phytohormones in morphological and anatomical responses of plants to flooding stress. In Plant Hormones under Challenging Environmental Factors; Ahammed, G.J., Yu, J.-Q., Eds.; Springer Science + Business Media: Dordrecht, Germany, 2016; pp. 117-132. [CrossRef]

14. Hattori, Y.; Nagai, K.; Furukawa, S.; Song, X.J.; Kawano, R.; Sakakibara, H.; Wu, J.; Matsumoto, T.; Yoshimura, A.; Kitano, H.; et al. The ethylene response factors SNORKEL1 and SNORKEL2 allow rice to adapt to deep water. Nature 2009, 460, 1026-1030. [CrossRef] [PubMed]

15. Fukao, T.; Xu, K.; Ronald, P.C.; Bailey-Serres, J. A variable cluster of ethylene response factor-Like genes regulates metabolic and developmental acclimation responses to submergence in rice. Plant Cell 2006, 18, 2021-2034. [CrossRef] [PubMed]

16. Licausi, F.; Weits, D.A.; Pant, B.D.; Scheible, W.R.; Geigenberger, P.; van Dongen, J.T. Hypoxia responsive gene expression is mediated by various subsets of transcription factors and miRNAs that are determined by the actual oxygen availability. New Phytol. 2011, 190, 442-456. [CrossRef] [PubMed]

17. Kerpen, L.; Niccolini, L.; Licausi, F.; van Dongen, J.T.; Weits, D.A. Hypoxic conditions in crown galls induce plant anaerobic responses that support tumor proliferation. Front Plant Sci. 2019, 10, 56. [CrossRef]

18. Shukla, V.; Lombardi, L.; Iacopino, S.; Pencik, A.; Novak, O.; Perata, P.; Giuntoli, B.; Licausi, F. Endogenous hypoxia in lateral root primordial controls root architecture by antagonizing auxin signaling in Arabidopsis. Mol. Plant. 2019, 12, 538-551. [CrossRef]

19. Visser, E.J.W.; Bogemann, G.M.; Blom, C.W.P.M.; Voesenek, L.A.C.J. Ethylene accumulation in waterlogged Rumex plants promotes formation of adventitious roots. J. Exp. Bot. 1996, 47, 403-410. [CrossRef]

20. Vidoz, M.L.; Loreti, E.; Mensuali, A.; Alpi, A.; Perata, P. Hormonal interplay during adventitious root formation in flooded tomato plants. Plant J. 2010, 63, 551-562. [CrossRef]

21. Wample, R.L.; Reid, D.M. The role of endogenous auxins and ethylene in the formation of adventitious roots and hypocotyl hypertrophy in flooded sunflower plants (Helianthus annus L.). Physiol. Plant. 1979, 45, 219-226. [CrossRef]

22. Yamamoto, F.; Kozlowski, T.T. Regulation by auxin and ethylene of responses of Acer negundo seedlings to flooding of the soil. Environ. Exp. Bot. 1987, 27, 329-340. [CrossRef]

23. Visser, E.J.W.; Heijink, C.J.; van Hout, K.J.G.M.; Voesenek, L.A.C.J.; Barendse, G.W.M.; Blom, C.W.P.M. Regulatory role of auxin in adventitious root formation in two spices of Rumex, differing in their sensitivity to waterlogging. Physiol. Plant. 1995, 93, 116-122. [CrossRef]

24. Visser, E.J.W.; Cohen, J.D.; Barendse, G.W.M.; Blom, C.W.P.M.; Voesenek, L.A.C.J. An ethylene-Mediated increase in sensitivity to auxin induces adventitious root formation in flooded Rumex palustris Sm. Plant Physiol. 1996, 112, 1687-1692. [CrossRef] [PubMed]

25. Cox, M.C.; Benschop, J.J.; Vreeburg, R.A.; Wagemaker, C.A.; Moritz, T.; Peeters, A.J.; Voesenek, L.A. The roles of ethylene, auxin, abscisic acid, and gibberellin in the hyponastic growth of submerged Rumex palustris petioles. Plant Physiol. 2004, 136, 2948-2960. [CrossRef] [PubMed]

26. Lee, Y.; Jung, J.W.; Kim, S.K.; Hwang, Y.S.; Lee, J.S.; Kim, S.H. Ethylene-Induced opposite redistributions of calcium and auxin are essential components in the development of tomato petiolar epinastic curvature. Plant Physiol. Biochem. 2008, 46, 685-693. [CrossRef] [PubMed]

27. Walters, J.; Osborne, D.J. Ethylene and auxin-Induced cell growth in relation to auxin transport and metabolism and ethylene production in the semi-Aquatic plant. Regnellidium Diphyllum Planta 1979, 146, 309-317. [CrossRef]

28. Summers, J.E.; Jackson, M.B. Anaerobic promotion of stem extension in Potamogeton pectinatus. Roles for carbone dioxide, acidification and hormones. Physiol. Plant. 1996, 96, 615-622. [CrossRef] 
29. Ridge, I.; Osborne, D.J. Wall extensibility, wall $\mathrm{pH}$ and tissue osmolality-Significance for auxin and ethylene-Enhanced petiole growth in semi-aquatic plants. Plant Cell Environ. 1989, 12, 383-393. [CrossRef]

30. Horton, R.F.; Samarakoon, A.B. Petiole growth in the celery-Leaved crowfoot (Ranunculus sceleratus L.): Effects of auxin-transport inhibitors. Aquat. Bot. 1982, 13, 97-104. [CrossRef]

31. Smulders, M.J.M.; Horton, R.F. Ethylene promotes elongation growth and auxin promotes radial growth in Ranunculus sceleratus petioles. Plant Physiol. 1991, 96, 806-811. [CrossRef]

32. Rijnders, J.G.H.M.; Barendse, G.W.M.; Blom, C.W.P.M.; Voesenek, L.A.C.J. The contrasting role of auxin in submergence-Induced petiole elongation in two species from frequently flooded wetlands. Physiol. Plant 1996, 96, 467-473. [CrossRef]

33. Cox, M.C.H.; Peeters, A.J.M.; Voesenek, L.A.C.J. The stimulating effects of ethylene and auxin on petiole elongation and on hyponastic curvature are independent processes in submerged Rumex palustris. Plant Cell Environ. 2006, 29, 282-290. [CrossRef] [PubMed]

34. Katsura, N.; Suge, H. Does ethylene induce elongation of the rice coleoptile through auxin? Plant Cell Physiol. 1979, 20, 1147-1150. [CrossRef]

35. Jackson, M.B. Ethylene-Promoted elongation: An adaptation to submergence stress. Ann. Bot. 2008, 101, 229-248. [CrossRef] [PubMed]

36. Mapelli, S.; Lombardi, L.; Bertani, A. The effect of growth substances on rice germination and growth under anoxia. Plant Physiol. (Life Sci. Adv.) 1993, 12, 9-15.

37. Hoson, T.; Masuda, Y.; Pilet, P.E. Auxin content in air and water grown rice coleoptiles. J. Plant Physiol. 1992, 139, 685-689. [CrossRef]

38. Yemelyanov, V.V.; Chirkova, T.V. Free forms of phytohormones in plants with different tolerance to the lack of oxygen under aeration and anaerobiosis. Bio. Comm. 1996, 41, 73-81. (In Russian)

39. Bakhtenko, E.Y.; Skorobogatova, I.V.; Karsunkina, N.P.; Platonov, A.V. Hormonal balance of wheat (Triticum aestivum L.) and oat (Avena sativa L.) under submergence and reparation. Agrochemistry 2008, 8, 33-41. (In Russian)

40. Mapelli, S.; Rocchi, P.; Bertany, A. ABA and IAA in rice seedlings under anaerobic conditions. Biol. Plant. 1986, 28, 57-61. [CrossRef]

41. Emel'yanov, V.V.; Kirchikhina, N.A.; Lastochkin, V.V.; Chirkova, T.V. Hormonal status in wheat and rice seedlings under anoxia. Russ. J. Plant Physiol. 2003, 50, 827-834. [CrossRef]

42. Blokhina, O.; Virolainen, E.; Fagerstedt, K.V. Antioxidants, oxidative damage and oxygen deprivation stress: A review. Ann. Bot. 2003, 91, 179-194. [CrossRef]

43. Choudhury, F.K.; Rivero, R.M.; Blumwald, E.; Mittler, R. Reactive oxygen species, abiotic stress and stress combination. Plant J. 2017, 90, 856-867. [CrossRef] [PubMed]

44. Janků, M.; Luhová, L.; Petřivalský, M. On the origin and fate of reactive oxygen species in plant cell compartments. Antioxidants 2019, 8, 105. [CrossRef] [PubMed]

45. Faseela, P.; Sinisha, A.K.; Brestič, M.; Puthur, J.T. Chlorophyll $a$ fluorescence parameters as indicators of a particular abiotic stress in rice. Photosynthetica 2019, 57, 108-115. [CrossRef]

46. Blokhina, O.B.; Chirkova, T.V.; Fagerstedt, K.V. Anoxic stress leads to hydrogen peroxide formation in plant cells. J. Exp. Bot. 2001, 52, 1179-1190. [CrossRef] [PubMed]

47. Lindberg, S.; Premkumar, A.; Rasmussen, U.; Schulz, A.; Lager, I. Phospholipases AtPLD $\zeta 1$ and AtPLD $\zeta 2$ function differently in hypoxia. Physiol. Plant. 2018, 162, 98-108. [CrossRef]

48. Blokhina, O.; Fagerstedt, K.V. Oxidative metabolism, ROS and NO under oxygen deprivation. Plant Physiol. Biochem. 2010, 48, 359-373. [CrossRef]

49. Sitbon, F.; Hennion, S.; Sundberg, B.; Little, C.H.; Olsson, O.; Sandberg, G. Transgenic tobacco plants coexpressing the Agrobacterium tumefaciens iaaM and iaaH genes display altered growth and indoleacetic acid metabolism. Plant Physiol. 1992, 99, 1062-1069. [CrossRef]

50. Eklöf, S.; Astot, C.; Sitbon, F.; Moritz, T.; Olsson, O.; Sandberg, G. Transgenic tobacco plants co-Expressing Agrobacterium iaa and ipt genes have wild-type hormone levels but display both auxin- and cytokininOverproducing phenotypes. Plant J. 2000, 23, 279-284. [CrossRef]

51. Murashige, T.; Skoog, F. A revised medium for rapid growth and bio assays with tobacco tissue cultures. Physiol. Plant. 1962, 15, 473-497. [CrossRef] 
52. Veselov, S.Y.; Kudoyarova, G.R.; Egutkin, N.L.; Gyuli-Zade, V.G.; Mustafina, A.R.; Kof, E.K. Modified solvent partitioning scheme providing increased specificity and rapidity of immunoassay for indole 3-acetic acid. Physiol. Plant. 1992, 86, 93-96. [CrossRef]

53. Chirkova, T.V.; Zhukova, T.M.; Goncharova, N.N.; Belonogova, V.A. Opredelenie stepeni pronitsaemosti membran kak sposob diagnostiki rasteniy na ustoychivost' $\mathrm{k}$ nedostatku kisloroda [Determination of the membrane permeability level as the method of plant diagnostic for resistance to oxygen deficiency]. Fiziol. Rast. Genet. 1991, 23, 68-75. (In Russian)

54. Baker, C.J.; Mock, N.M. An improved method for monitoring cell-Death in cell-suspension and leaf disc assays using Evans blue. Plant Cell Tissue Organ Cult. 1994, 39, 7-12. [CrossRef]

55. Bozhkov, P.V.; Filonova, L.H.; von Arnold, S. A key developmental switch during Norway spruce somatic embryogenesis is induced by withdrawal of growth regulators and is associated with cell death and extracellular acidification. Biotechnol. Bioeng. 2002, 77, 658-667. [CrossRef] [PubMed]

56. Chirkova, T.V.; Novitskaya, L.O.; Blokhina, O.B. Lipid peroxidation and antioxidant systems under anoxia in plants differing in their tolerance to oxygen deficiency. Russ. J. Plant Physiol. 1998, 45, 55-62.

57. Rubin, B.A.; Merzlyak, M.N.; Juferova, S.G. Oxidation of lipid components in isolated chloroplasts under lighting. The substrates and products of lipid peroxidation. Sov. Plant Physiol. 1976, 23, 254-261.

58. Minibayeva, F.; Kolesnikov, O.; Chasov, A.; Beckett, R.P.; Lüttge, S.; Vylegzhanina, N.; Buck, F.; Böttger, M. Wound-Induced apoplastic peroxidase activities: Their roles in the production and detoxification of reactive oxygen species. Plant Cell Environ. 2009, 32, 497-508. [CrossRef]

59. Gay, C.; Gebicki, J.M. A critical evaluation of the effect of sorbitol on the ferric-Xylenol orange hydroperoxide assay. Anal. Biochem. 2000, 284, 217-220. [CrossRef]

60. Olatunji, D.; Geelen, D.; Verstraeten, I. Control of endogenous auxin levels in plant root development. Int. J. Mol. Sci. 2017, 18, 2587. [CrossRef]

61. Zhang, J.; Lin, J.E.; Harris, C.; Campos Mastrotti Pereira, F.; Wu, F.; Blakeslee, J.J.; Peer, W.A. DAO1 catalyzes temporal and tissue-Specific oxidative inactivation of auxin in Arabidopsis thaliana. Proc. Natl. Acad. Sci. USA 2016, 113, 11010-11015. [CrossRef]

62. Yang, X.; Jansen, M.J.; Zhang, Q.; Sergeeva, L.; Ligterink, W.; Mariani, C.; Rieu, I.; Visser, E.J.W. A disturbed auxin signaling affects adventitious root outgrowth in Solanum dulcamara under complete submergence. J. Plant Physiol. 2018, 224-225, 11-18. [CrossRef]

63. Lastochkin, V.V.; Yemelyanov, V.V.; Chirkova, T.V. Aktivnost' peroksidazy v prorostkakh pshenitsy i risa v svyazi s vozdeystviem anoksii [Peroxidase activity in wheat and rice seedlings under anoxia]. Biol. Comm. 2000, 45, 59-64. (In Russian)

64. Tognetti, V.B.; Mühlenbock, P.; Van Breusegem, F. Stress homeostasis-The redox and auxin perspective. Plant Cell Environ. 2012, 35, 321-333. [CrossRef] [PubMed]

65. Ivanchenko, M.G.; den Os, D.; Monshausen, G.B.; Dubrovsky, J.G.; Bednarova, A.; Krishnan, N. Auxin increases the hydrogen peroxide $\left(\mathrm{H}_{2} \mathrm{O}_{2}\right)$ concentration in tomato(Solanum lycopersicum) root tips while inhibiting root growth. Ann. Bot. 2013, 112, 1107-1116. [CrossRef] [PubMed]

66. Peer, W.A.; Cheng, Y.; Murphy, A.S. Evidence of oxidative attenuation of auxin signaling. J. Exp. Bot. 2013, 64, 2629-2639. [CrossRef] [PubMed]

67. Nguyen, H.T.H.; Umemura, K.; Kawano, T. Indole-3-Acetic acid-Induced oxidative burst and an increase in cytosolic calcium ion concentration in rice suspension culture. Biosci. Biotech. Bioch. 2016, 80, 1546-1554. [CrossRef]

68. Huang, A.; Wang, Y.; Liu, Y.; Wang, G.; She, X. Reactive oxygen species regulate auxin levels to mediate adventitious root induction in Arabidopsis hypocotyl cuttings. J. Integr. Plant Biol. 2019. [CrossRef]

69. Liszkay, A.; van der Zalm, E.; Schopfer, P. Production of reactive oxygen intermediates $\left(\mathrm{O}_{2}{ }^{-}, \mathrm{H}_{2} \mathrm{O}_{2}\right.$, and $\left.\mathrm{OH}\right)$ by maize roots and their role in wall loosening and elongation growth. Plant Physiol. 2004, 136, 3114-3123. [CrossRef]

70. Pavlů, J.; Novák, J.; Koukalová, V.; Luklová, M.; Brzobohatý, B.; Černý, M. Cytokinin at the crossroads of abiotic stress signalling pathways. Int. J. Mol. Sci. 2018, 19, 2450. [CrossRef]

71. Sohag, A.A.M.; Tahjib-Ul-Arif, M.; Brestič, M.; Afrin, S.; Sakil, M.d.A.; Hossain, M.d.T.; Hossain, M.A.; Hossain, M.d.A. Exogenous salicylic acid and hydrogen peroxide attenuate drought stress in rice. Plant Soil Environ. 2020. [CrossRef] 
72. Ishizawa, K.; Esashi, Y. Co-operation of ethylene and auxin in the growth regulation of rice coleoptile segments. J. Exp. Bot. 1983, 34, 74-82. [CrossRef]

73. Horton, R.F. The effect of ethylene and other regulators on coleotile growth of rice under anoxia. Plant Sci. 1991, 79, 57-62. [CrossRef]

74. Kato-Noguchi, H. Effects of plant hormones on the activity of alcohol dehydrogenase in lettuce seedlings. J. Plant Physiol. 2000, 157, 223-225. [CrossRef]

75. Mapelli, S.; Locatelli, F. The relation of rice coleoptiles, auxin-Binding protein, and protein synthesis to anoxia and indoleacetic acid. Russ. J. Plant Physiol. 1995, 42, 624-629.

76. Dharmasiri, N.; Dharmasiri, S.; Estelle, M. The F-box protein TIR1 is an auxin receptor. Nature 2005, 435, 441-445. [CrossRef] [PubMed]

77. Kant, S.; Bi, Y.M.; Zhu, T.; Rothstein, S.J. SAUR39, a Small Auxin-Up RNA gene, acts as a negative regulator of auxin synthesis and transport in rice. Plant Physiol. 2009, 151, 691-701. [CrossRef] [PubMed]

78. Huang, W.; Peng, S.; Xian, Z.; Lin, D.; Hu, G.; Yang, L.; Ren, M.; Li, Z. Overexpression of a tomato miR171 target gene SIGRAS24 impacts multiple agronomical traits via regulating gibberellin and auxin homeostasis. Plant Biotechnol. J. 2017, 15, 472-488. [CrossRef]

79. Hou, Y.; Jiang, F.; Zheng, X.; Wu, Z. Identification and analysis of oxygen responsive microRNAs in the root of wild tomato (S. habrochaites). BMC Plant Biol. 2019, 19, 100. [CrossRef]

(C) 2020 by the authors. Licensee MDPI, Basel, Switzerland. This article is an open access article distributed under the terms and conditions of the Creative Commons Attribution (CC BY) license (http://creativecommons.org/licenses/by/4.0/). 